\title{
Optimization of Office Building Façades in a Warm Summer Continental Climate
}

\author{
Allan Hani, Teet-Andrus Koiv \\ Environmental Department, Tallinn University of Technology, Tallinn, Estonia. \\ Email: allan.hani@rkas.ee
}

Received March $28^{\text {th }}, 2012$; revised July $20^{\text {th }}, 2012$; accepted July $27^{\text {th }}, 2012$

\begin{abstract}
A typical office building model with conventional use and contemporary building systems was developed for façade optimization in continental climate. Wall, glazing area and window parameters were taken as the main variables. The objective function of optimization task described in this article is the minimization of cooling and heating energy consumption. The office building façades optimization was carried out using a combination of IDA Indoor Climate and Energy 4.5 and GenOpt. The process is described in detail so that the approach may be emulated. A hybrid multidimensional optimization algorithm GPSPSOCCHJ was used in calculation process. The optimization results are presented in four quick selection charts to assist architects, designers and real estate developers make suitable early stage façade selection decisions.
\end{abstract}

Keywords: Optimization; Envelope Design; Passive Solar Control; Energy Efficiency; Office Building

\section{Introduction}

Much research describes building simulation software as a tool for calculation process. IDA Indoor Climate and Energy, TRNSYS, Energy Plus, eQuest, DOE-2, etc. are well-known programs used to create building models and to perform the necessary energy consumption and indoor climate condition simulations. These tools have been tested and validated through real experimental cases. The simulation tools are usually used to perform limited numbers of single runs to give an overview and conclusions about a defined task. As these programs are used to conduct hourly based calculations over the full year, sufficiently accurate energy consumption results are achieved. The probability for these results to run across the Pareto frontier optimum solutions is actually very low. A possibility to find optimal solution is to use a "brute force" search. This method needs a huge calculation resource due to the fact that all possible combinations are evaluated [1].

A reasonable approach to achieving the optimal solution is to combine building simulation tools and optimization software. Optimization software can be customized for the particular research. Another possibility is to use an existing solution such as Lawrence Berkeley National Laboratory branded GenOpt or Matlab's Optimization Toolbox.

Different optimization algorithms are implemented in optimization software. Generally the algorithms are di- vided into: single and multi-objective. Selection of the algorithm depends on the constraints and/or the number of functions to be optimized. Multi-objective functions can be solved, for example, with Matlab Optimization Toolbox, single objective with GenOpt.

Technically the most challenging is to combine simulation and optimization tools. All the earlier studies indicate problems with computational hardware power-the calculation time is in relation to the number of variables and functions.

Daniel Tuhus-Dubrow, Moncef Krarti have used DOE-2, Perl application and Matlab for the optimization of a residential building envelope shape [2,3]. TRNSYS and Matlab calculations were done for cooling system optimization by K. F. Fong, V. I. Hanby, T. T. Chow [4]. Hanna Jedrzejuk, Wojciech Marks used a tailor-made solution for the optimization of the walls and heat source for a building [5]. Gianluca Rapone, Onorio Saro had researched office building shading solutions with a combination of Energy Plus and GenOpt in 2011 [6]. Energy Plus and GenOpt are combined for indoor comfort and hydronic heating optimization by Natasa Djuric, Vojislav Novakovic, Johnny Holst, Zoran Mitrovic [7]. Multilayered walls have been optimized with genetic algorithms by V. Sambou, B. Lartigue, F. Monchoux, M. Adj [8]. Energy Plus and Matlab was used by Jingran Ma, Joe Qin, Timothy Salsbury, Peng Xu to show the demand controlled systems economic efficiency in [9]. Weimin 
Wang, Radu Zmeureanu, Hugues Rivard have published green building optimization concept with multi-objective genetic algorithms [10]. M. Mossolly, K. Ghali, N. Ghaddar have used Matlab to optimize control strategy for an air-conditioning system [11]. HVAC system optimization results were published by $\mathrm{Lu} \mathrm{Lu}$, Wenjian Cai, Lihua Xie, Shujiang Li, Yeng Chai Soh [12]. TRNSYS and GenOpt thermal comfort has been optimized by Laurent Magnier, Fariborz Haghighat [13]. VAV system optimal supply air temperature research was published by Fredrik Engdahl, Dennis Johansson [14]. Excel and Matlab combination for building retrofit strategies calculation has been carried out by Ehsan Asadi, Manuel Gameiro da Silva, Carlos Henggeler Antunes, Lukss Dias [15]. Single and multiobjective approaches for building façade overall energy efficiency were demostrated by Giovanni Zemella, Davide De March, Matteo Borrotti, Irene Poli [16]. Energy conser vation possibilities in buildings have been studied by V. Siddharth, P. V. Ramakrishna, T. Geetha, Anand Sivasubramaniam with DOE-2.2 and genetic algorithms [17]. Multi-parameter thermal optimization (APACHE software) has been done by A. Saporito, A. R. Day, T. G. Karayiannis, F. Parand [18]. A comprehensive study of building energy consumption and indoor environment optimization was done by Mohamed Hamdy, Ala Hasan, Kai Siren (Matlab + IDA ICE combination) [19].

Micheal Wetter stated in 2004 the following: "Discussions with IDA ICE developer showed that IDA-ICE might indeed be a promising tool for use with our optimization algorithms (GenOpt). However, without extensive numerical experiments and code analysis, it is not possible to conclude that IDA-ICE satisfies our requirements" [20].

The current research is based on a combination of IDA ICE and GenOpt. The IDA ICE and GenOpt combination has already been used by Ala Hasan, Mika Vuolle and Kai Siren [21]. Our paper describes the dynamic of window area, solar factor versus cooling, heating energy consumption in different cardinal directions. Due to the fact that the façade energy consumption is evaluated, other building envelope parameters and internal heat gains are handled as constants.

Hendrik Voll and Teet-Andrus Kõiv have published an article about cooling power demand estimation principles and different parameter relations for commercial buildings [22].

Our research is focused on heating and cooling energy consumption strategies for office buildings. Early stages of design affect future energy consumption for the building the most. The objective of this research is to develop quick selection charts for different cardinal directions in relation to window area and other envelope parameters.

\section{Methods}

\subsection{Simulation-Optimization Approach}

The theoretical approach for the building shape was created in the IDA Indoor Climate and Energy 4.5 environment. A square shaped three floor model (floor height 3.0 $\mathrm{m}$ ) is indicated in Figure 1.

A typical office building is very often a multi-storey compact structure. Therefore, calculations were done in this case for the first floor to eliminate ground and roof physical effects.

First step, the IDA ICE mathematical model run creates a substantial ida_lisp.ida file with all defined data and relations between the parameters. The main structure of ida_lisp.ida consists of files, constants, tables, modules, connections, boundaries, start values, integration and $\log$. To understand the relationships between different parameters is technically challenging. The full logic has to be understood and tested. For example, an increase of window area must decrease the same face wall area and vice versa in optimization calculations. As well the solar factor and shading coefficient have mathematical relation between them. To create the base IDA ICE model file for optimization calculations we renamed the ida_lisp.ida file to templ.ida and modified the envelope parameters mostly in the modules section. The basic scheme of the optimization is shown in Figure 2.

The convenient search and study of certain parameters in the ida_lisp.ida file can be achieved by giving clearly identified parameter values in the IDA ICE model for the particular module (glass, wall, etc.). Understanding of the total ida file puzzle is time-consuming, but unavoidable for optimization of IDA ICE calculation results with optimization tools.
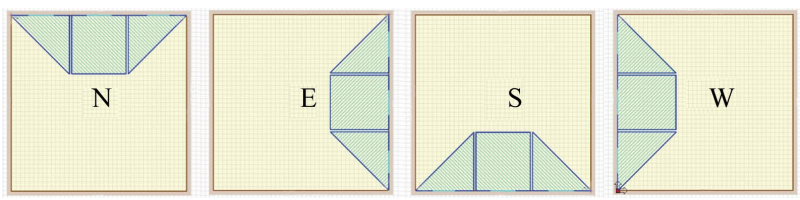

Figure 1. Shape of theoretical calculation model.

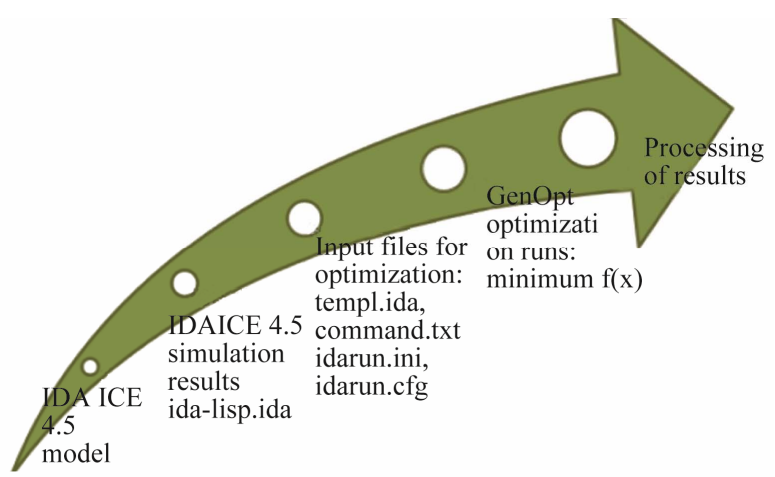

Figure 2. IDA ICE and GenOpt simulation-optimization process. 
The second step is to create a command.txt file and define variables for the optimization process. The variables are indicated in Table 1. GenOpt can handle discrete and continuous variables.

Pre-processing relations between different building parameters are also described into command.txt file. For the current paper wall-window and solar factor-shading coefficient relations were defined (see following code).

Vary $\{$ Parameter $\{$ Name $=$ Alwin; $\operatorname{Min}=1.2$; Ini $=$ 1.2; $\operatorname{Max}=10.8 ;$ Step $=1.2 ;\}$

Function $\{$ Name $=$ A1wall; Function $=$ "subtract $(12.0$, $\%$ A1win \%)"; $\}$

Function $\{$ Name $=$ A2wall; Function $=$ "subtract (11.124, \%A1win\%)";

Parameter $\{\mathrm{Name}=\mathrm{sfGl} ; \mathrm{Min}=0.2 ; \mathrm{Ini}=0.2 ; \mathrm{Max}=$ $0.8 ;$ Step $=0.2 ;\}$

Function $\{$ Name $=\mathrm{tGl}$; Function $=$ "multiply $(0.87$, \%sfGl\%)"; \}

Furthermore, the command.txt file must also contain information about the optimization algorithm [23].

The actual optimization process was carried out with GPSPSOCCHJ algorithm. GPSPSOCCHJ is a hybrid multidimensional optimization algorithm which uses generalized pattern search (GPS) for the first stage search and particle swarm optimization (PSO) Hooke Jeeves algorithm as a fine search for the defined discrete and continuous variables function solution.

The configuration file idarun.cfg is written only once and it describes the IDA ICE simulation run parameters. The third essential file idarun.ini contains information about the locations of template, input, log, output, configuration and optimization files. The most important idarun.ini information is the objective function (in our case minimization function) definition. Constraints can be set to the optimization function, if necessary. The first stage of post-processing is also done here. For the different cardinal directions, our study uses the following IDA ICE templ.ida related code:

Name1 = Energ_kWh;

Function $1=$ "add $(\%$ Cool_kWh\%, \%Heat_kWh\%)"

Name2 = negCool_kWh:

Delimiter2 = "Emeterlocool.Totenergy";

Name3 = Cool_kWh;

Function3 = "multiply (\% neCool_kWh \%, -1)"

Name4 $=$ Heat_kWh;

Delimiter4 = "Etelocheat.Totenergy";

Name5 $=$ WinN_SF;

Function $5=\%$ SFG $1 \%$;

Name6 $=$ Win_m2;

Function $6=\%$ A 1 win $\%$;

Name7 = Wall_m2;

Function $7=\% \bar{A} 1$ wall $\%$;

Our minimization leading function $\min f(x)$ is the minimization sum of cooling and heating energy related to external wall-glass parameters. The delimited energy information is recorded separately; therefore we can also present the balance between cooling and heating individually.

Four optimization runs were carried out.

\subsection{Outdoor Climate Conditions}

The test reference years are widely used for energy performance calculations and indoor climate analysis. Hourly based outdoor climate data (dry-bulb air temperature, relative humidity, wind speed, direct solar radiation and diffuse radiation on horizontal surfaces for 8784 hours) was used to create the mathematical model for IDA ICE 4.5 calculations [24]. Comparability of current study results for other climatic areas can be done through monthly and yearly average parameters which are indicated in Table 2.

\subsection{Indoor Environment}

Category II requirements from EN 15251:2007 were taken as the basis for defining indoor climate in simulation-optimization models. This category is considered as the normal expectation for new buildings and renovations according to reasonable indoor climate and energy efficiency levels [25].

Table 1. Optimization parameters.

\begin{tabular}{lll}
\hline Variable & Type & Value \\
\hline Window area & Continuous & $10 \%-90 \%$, step $10 \%$ \\
Glass solar factor & Continuous & $0.2-0.8$, step 0.2 \\
Cardinal directions & - & North, East, South, West
\end{tabular}

Table 2. Test reference year parameters.

\begin{tabular}{cccccc}
\hline Month temperture & $\begin{array}{c}\text { Air } \\
{ }^{\circ} \mathrm{C}\end{array}$ & $\begin{array}{c}\text { Relative } \\
\text { humidity } \\
\%\end{array}$ & $\begin{array}{c}\text { Wind } \\
\text { speed } \\
\mathrm{m} / \mathrm{s}\end{array}$ & $\begin{array}{c}\text { Direct dolar } \\
\text { radition } \\
\mathrm{MJ} / \mathrm{m}^{2}\end{array}$ & $\begin{array}{c}\text { Diffuse rdiation } \\
\text { on hozontal surf. } \\
\mathrm{MJ} / \mathrm{m}^{2}\end{array}$ \\
\hline Jan & -3.0 & 90 & 5 & 35.0 & 39.2 \\
Feb & -5.2 & 89 & 4 & 93.4 & 82.0 \\
Mar & -0.1 & 76 & 4 & 308.1 & 144.2 \\
Apr & 4.0 & 77 & 4 & 254.4 & 190.2 \\
May & 11.2 & 70 & 4 & 493.3 & 269.6 \\
Jun & 14.1 & 73 & 3 & 497.8 & 306.1 \\
Jul & 17.2 & 77 & 3 & 606.1 & 290.8 \\
Aug & 15.7 & 81 & 3 & 453.6 & 229.7 \\
Sep & 10.8 & 82 & 4 & 259.0 & 161.3 \\
Oct & 5.8 & 87 & 4 & 143.8 & 82.9 \\
Nov & -0.1 & 91 & 4 & 68.2 & 37.0 \\
Dec & -2.5 & 86 & 5 & 49.7 & 20.8 \\
Avg & 5.7 & 81 & 4 & 271.9 & 154.5 \\
\hline
\end{tabular}


Indoor climate comfort can be described by two different indexes: PMV and PPD. These take into account the influence of six thermal comfort parameters: clothing, activity, air- and mean radiant temperature, air velocity and humidity. Table 3 indicates the indoor climate parameters used for the calculations.

\subsection{Office-Building Conventional Use}

Internal heat gains in the average office area are presented in Figure 3 [26]. The profile and detailed loads for occupants, equipment and lights were used for calculations in the IDA ICE 4.5 mathematical model. The profile

Table 3. Indoor climate criteria.

\begin{tabular}{ll}
\hline $\begin{array}{l}\text { Indoor environment parameters } \\
\begin{array}{l}\text { Thermal conditions in winter for } \\
\text { energy calculations }\end{array}\end{array}$ & $20^{\circ} \mathrm{C}-24^{\circ} \mathrm{C}\left[21^{\circ} \mathrm{C}\right]$ \\
$\begin{array}{l}\text { Thermal conditions in summer for } \\
\text { energy calculations }\end{array}$ & $23^{\circ} \mathrm{C}-26^{\circ} \mathrm{C}\left[25^{\circ} \mathrm{C}\right]$ \\
Personnel insulative clothing & $\sim 0.5$ clo summer \\
Personnel activity level & $\sim 1.0$ clo winter \\
Airflow to zones & $\sim 1.2$ met \\
CO ${ }_{2}$ level (outdoor 350 ppm) & $71 / \mathrm{s} \mathrm{person}$ \\
Relative humidity & {$\left[1.41 / \mathrm{s} \mathrm{m}{ }^{2}\right]<850 \mathrm{ppm}$} \\
$\begin{array}{l}\text { Allowed parameter deviation } \\
\text { (working hours) }\end{array}$ & $25 \%-60^{\circ}$ \\
\hline
\end{tabular}

is used from Monday to Friday-in the theoretical calculations internal heat gains were not estimated for the weekend.

\subsection{Building Envelope and Technical Services}

The building enclosure's U-values were selected to be challenging but possible to achieve in construction practice for a "low energy building" [27]. Typical thermal bridge values have been used in the calculations (the effect of thermal bridges heat loss achieves more importance in case superb heat transfer coefficients are utilized). HVAC systems and other IDA ICE 4.5 simulation input parameters are indicated in Table 4.

Table 4. Building envelope and HVAC systems parameters.

\begin{tabular}{ll}
\hline External wall heat transfer coefficient $\mathrm{U}_{\mathrm{w}}$ & $0.14 \mathrm{~W} /\left(\mathrm{m}^{2} \mathrm{~K}\right)$ \\
\hline Window glass heat transfer coefficient $\mathrm{U}_{\mathrm{wg}}$ & $0.8 \mathrm{~W} /\left(\mathrm{m}^{2} \mathrm{~K}\right)$ \\
Window frame heat transfer coefficient $\mathrm{U}_{\mathrm{wf}}$ & $2.0 \mathrm{~W} /\left(\mathrm{m}^{2} \mathrm{~K}\right)$ \\
External wall/ external wall thermal bridge & $0.08 \mathrm{~W} / \mathrm{K} /(\mathrm{m}$ joint $)$ \\
External window or door perimeter thermal & $0.03 \mathrm{~W} / \mathrm{K} /(\mathrm{m}$ perimeter $)$ \\
bridge & $1.0 \mathrm{~m}^{3} /\left(\mathrm{h} \mathrm{m}^{2}\right)$ \\
Infiltration q & \\
Building wind exposure & Semi-exposed \\
Air handling unit $(\mathrm{AHU})$ heat recovery & $80 \%$ \\
AHU SFP & $1.7 \mathrm{~kW} /\left(\mathrm{m}^{3} / \mathrm{s}\right)$ \\
AHU $\mathrm{t}_{\text {supply }}$ to zone $\left(\mathrm{t}_{\mathrm{AHU}}\right.$ supply $\left.=16^{\circ} \mathrm{C}\right)$ & $18^{\circ} \mathrm{C}$ \\
\hline
\end{tabular}

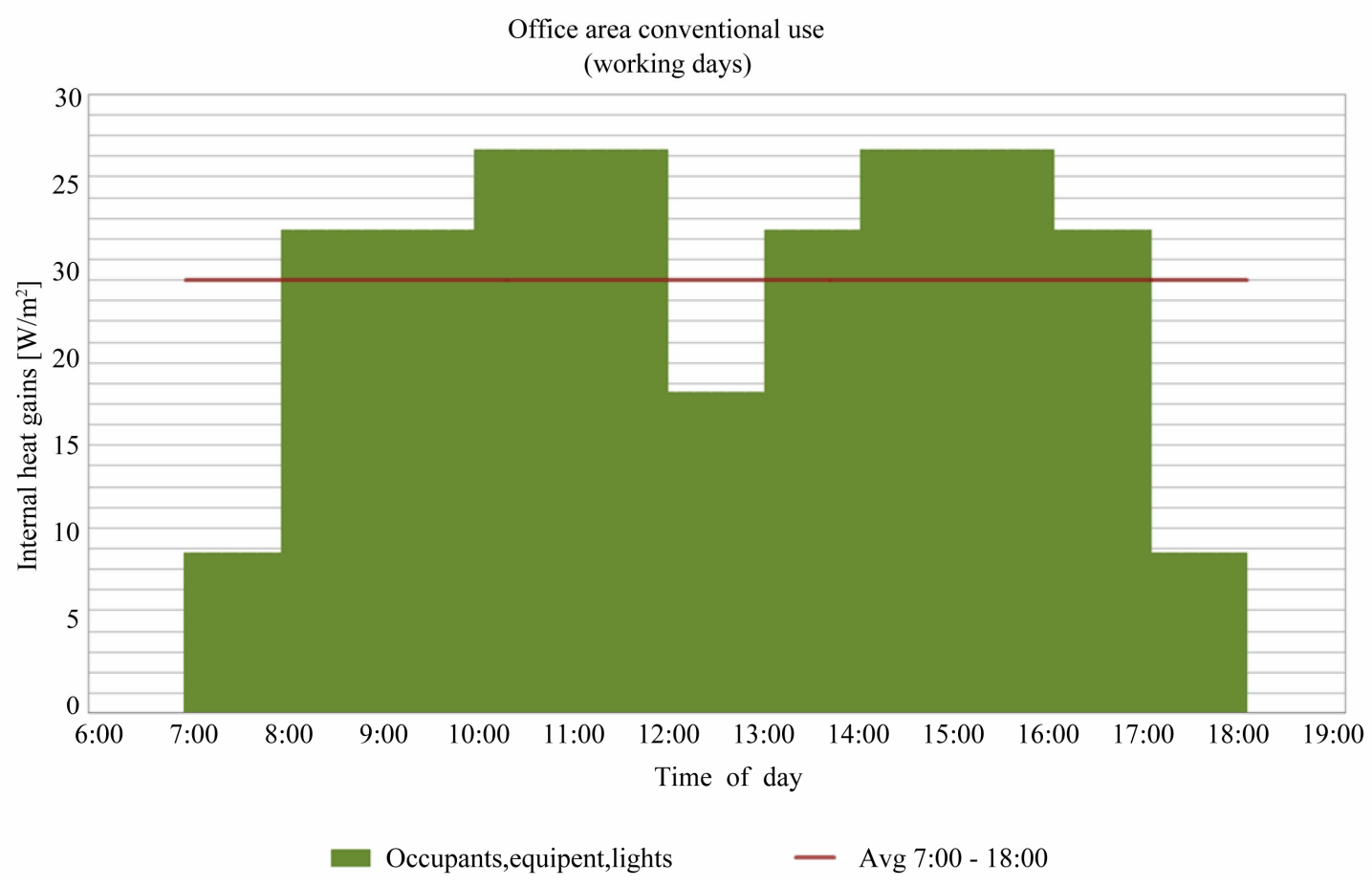

Figure 3. Typical office area internal heat gains. 


\section{Results}

GenOpt optimization solver calculated through a total of 658 iterations during four optimization runs for different façade directions. The calculation and post-processing results are presented in the following 4 figures (Figures 4-7).

Total yearly specific energy consumption is the average of four façade selected net energy consumptions $\left(\mathrm{kWh} / \mathrm{m}^{2} \mathrm{a}\right)$.

Figures 4-7 detailed explanation: on primary axis net energy consumption for façade heating and cooling is presented. Secondary axis shows the window/wall ratio in percentages. Horizontal axis show glass solar factor (7 - 8 different window/wall ratio cases for each-see the blue dots). The selection of optimum starts from the directive window/wall ratio (e.g. from architect) - four different cases are possible for current cardinal direction related to glass solar factor.

\section{Discussion}

Window/wall area ratio (indicated in secondary axis) shall be the primary directive selection parameter (daylight window design parameters can be taken as additional constraints to make the first selection for window area [22]). Energy consumption is directly related to window/wall ratio and window glass parameters.

In the warm summer continental climate conditions for North and East façades the solar factor 0.4 can be suggested due to higher heat energy demand. South and West façades must have a solar factor as good as possible (in our case 0.2). High solar factor values must be prevented for all façade cardinal directions even in a cold climate.

These quick selection figures (Figures 4-7) can be used by building architects and developers to make a first quick-selection of building façades energy consumption. According to the Energy Performance of Buildings Directions (EPBD) the EU member states must define nearly zero energy buildings levels. For new buildings it will be a challenging task to achieve these levels by 2020, therefore, the current selection charts provide additional information for early stage building energy consumption estimation.

\subsection{Sensitivity Analysis}

To study the sensitivity of the above results we carried out some single runs for a double skin façade. The same principles are applicable for different cardinal directions. The internal envelope must be well thermally insulated for current climate conditions. Total solar factor (for both internal and external glazing) shall also have the suggested values. For double skin façades the window U-value has a direct effect on energy consumption for windows.

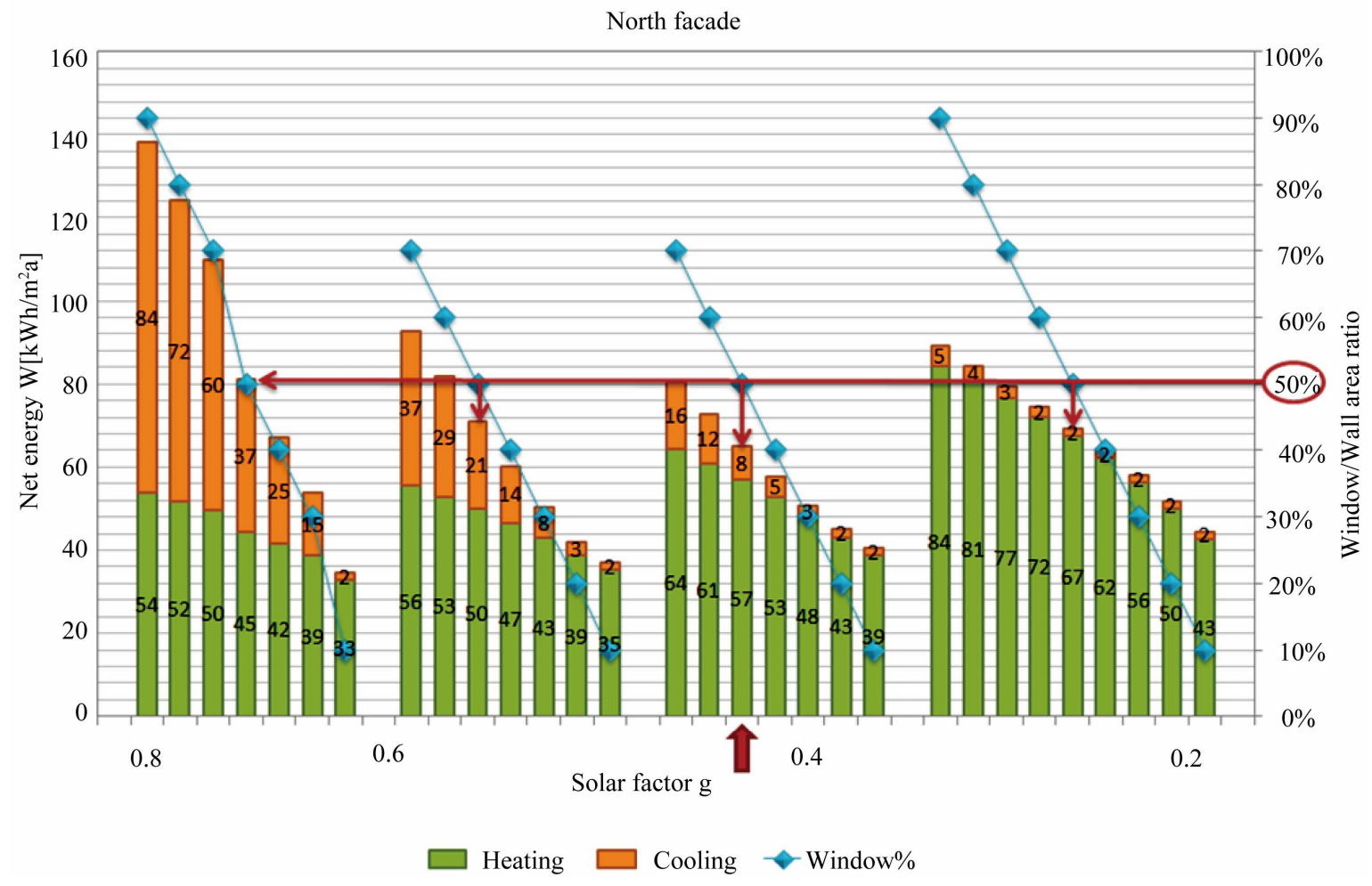

Figure 4. North façade optimization results. 


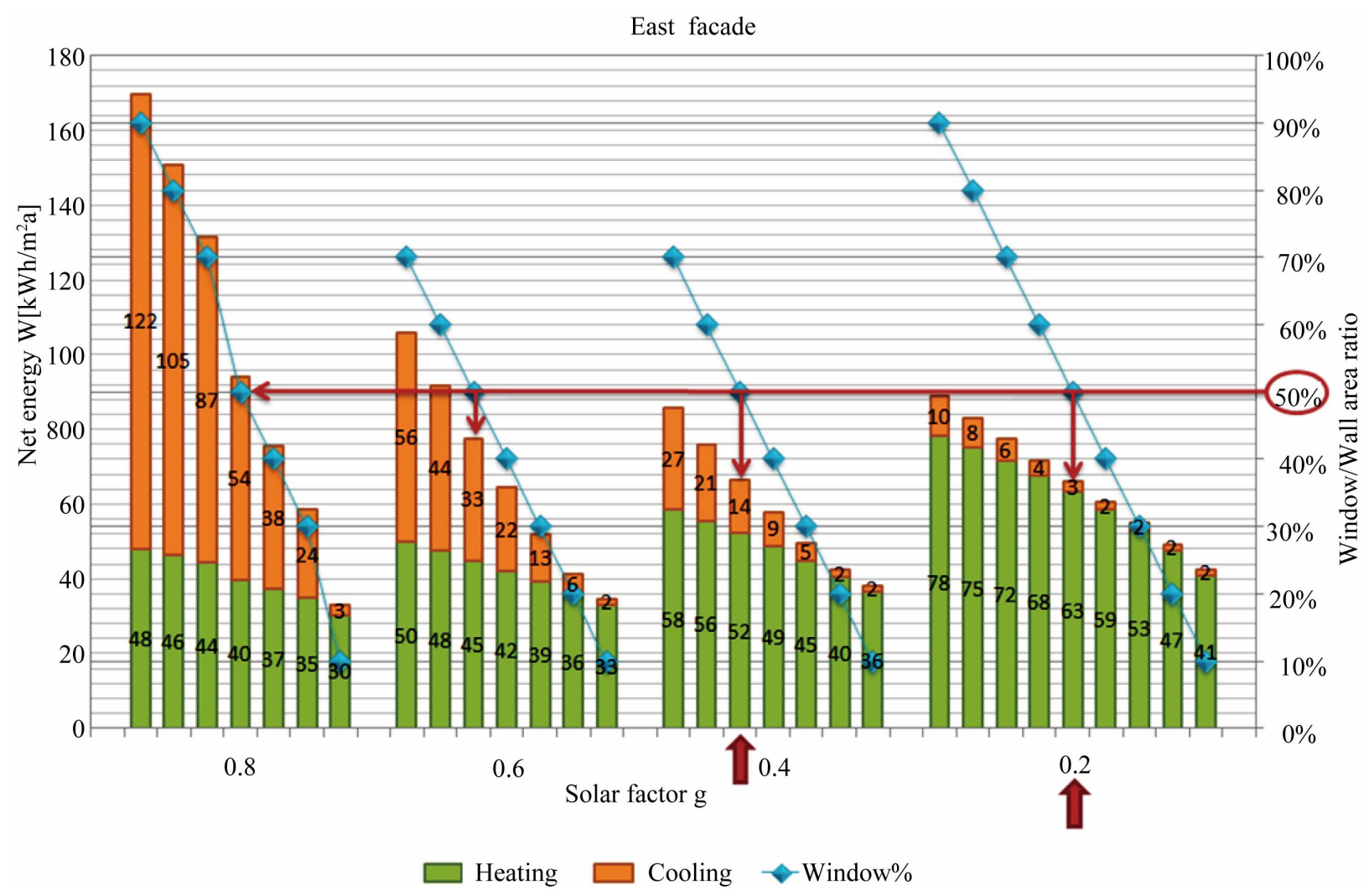

Figure 5. East façade optimization results.

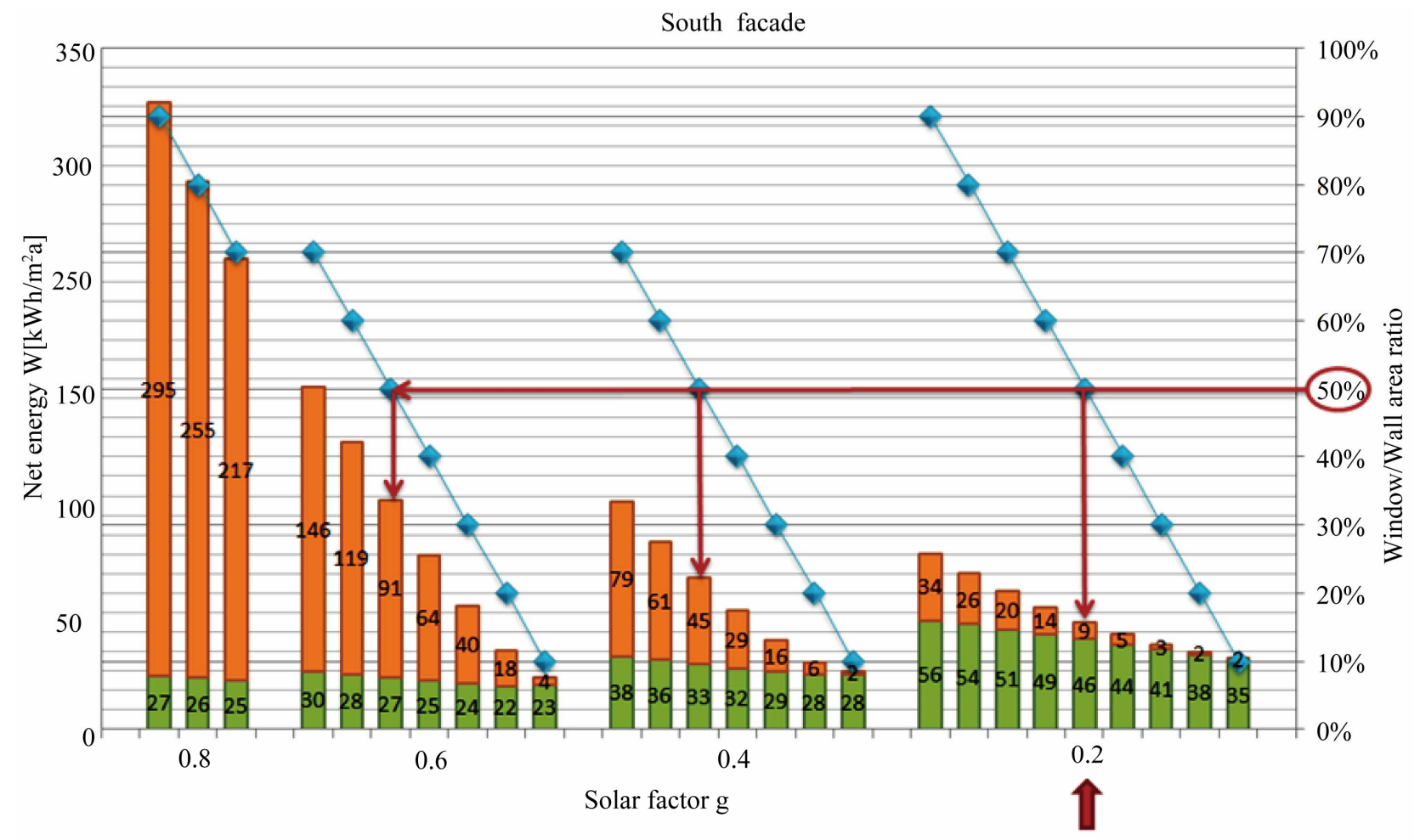

$\square$ Heating $\square$ Cooling $\quad$ Window\%

Figure 6. South façade optimization results. 


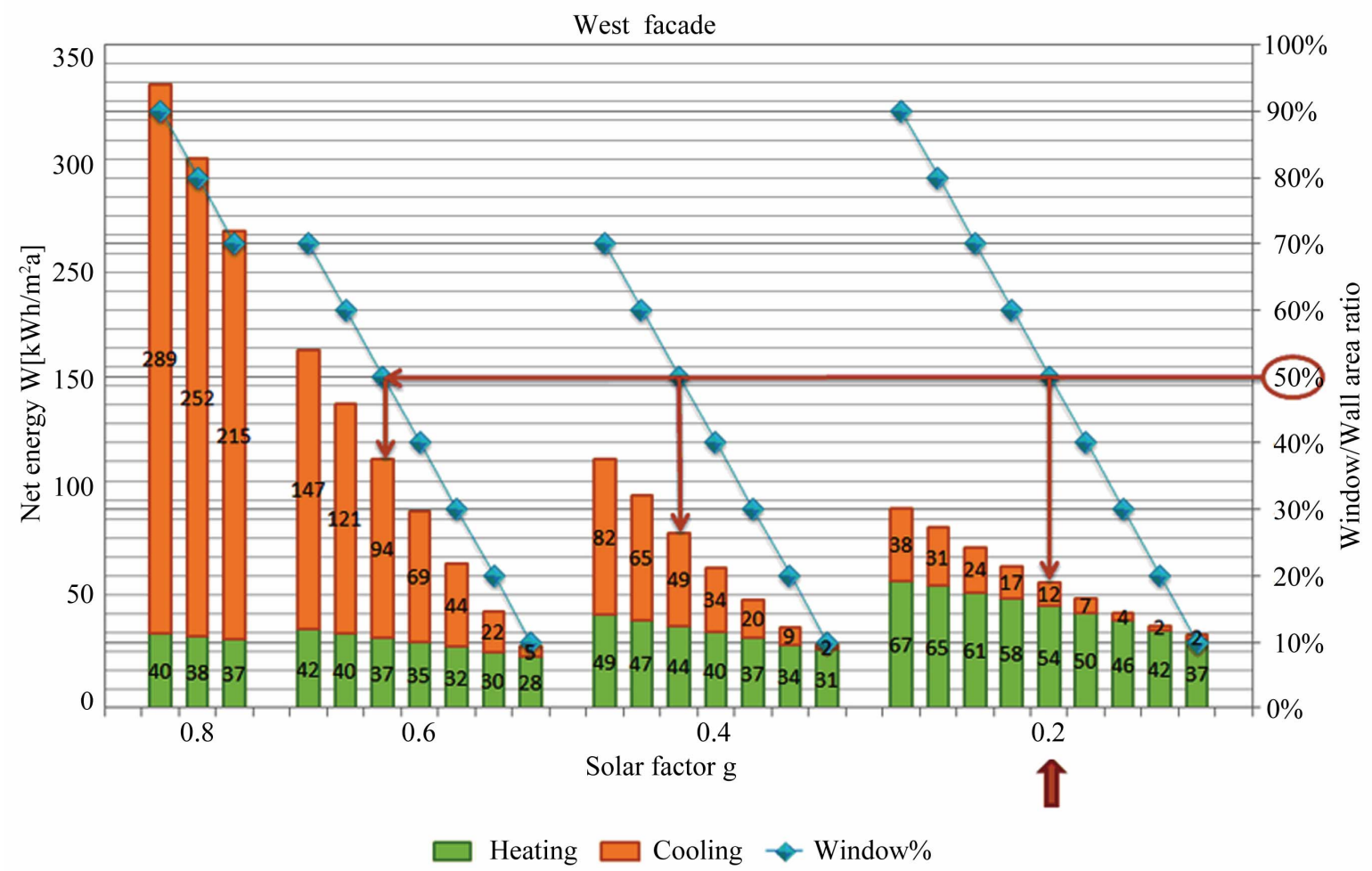

Figure 7. West façade optimization results.

Furthermore, Tobias Rosencrantz [28] has published heating net energy results for façades in the different cardinal directions for similar climatic conditions in Sweden and there is only slight deviation with our results.

Several IDA ICE single runs showed an acceptable indoor climate with solar factor 0.2 and 0.4 .

\section{Conclusions}

The structure and importance of this work is presented as follows:

Creation of theoretical office building simulation model suitable for defining external wall window mathematical problem for optimization. Hourly based test reference year parameters were used for the external climate data. Indoor climate parameters are based on EN15251:2007 and the conventional use of the building [26].

The problem of combining IDA Indoor Climate and Energy building simulation model and the GenOpt optimization tool has been overcome. The main steps of the optimization approach have been described above. In addition, example code for the optimization files has been indicated.

Quick selection charts (Figures 4-7) have been developed for different façade directions and the results have been verified. In the quick selection charts heating, cooling net energy consumption for façades, window/wall ratio and window solar factor relationships are indicated.
Future new building solutions will have to follow nearly zero energy buildings legislation in EU member states. The current research helps to select office building façade in the early design stage. Architects often use a lot of glass in conventional office building façades and this will result in high energy consumption and life cycle costs. The energy consumption minimization shall be done based on the Figures 4-7 in warm summer continental climate as the figures clearly present the relationship of different parameters (cardinal direction, window area, solar factor, specific cooling and heating energy consumption).

Further research topics should be related to other optimization tools. GenOpt, as currently used, solves single objective problems. In future, multi-objective solvers shall be applied to incorporate more detailed indoor environment (PMV, PPD) considerations into the façade investigation which has been dealt with here.

To use different double skin façade parameters, combined with thermal comfort, will be another interesting field of study. Moreover, economical calculations could be included as one of the multi-objective variables in further research.

\section{Acknowledgements}

Estonian Ministry of Education and Research is greatly acknowledged for funding and supporting this study. European Social Foundation financing task 1.2.4 Coop- 
eration of Universities and Innovation Development, Doctoral School project "Civil Engineering and Environmental Engineering" code 1.2.0401.09-0080 has made publishing of this article possible.

\section{REFERENCES}

[1] P. G. Ellis, B. T. Griffith, N. Long, P. Torcellini and D. Crawley, "Automated Multivariate Optimization Tool for Energy Analysis," IBPSA SimBuild Conference, Cambridge, 2-4 August 2006, 7 p.

[2] D. Tuhus-Dubrow and M. Krarti, "Genetic-Algorithm Based Approach to Optimize Building Envelope Design for Residential Buildings," Building and Environment, Vol. 45, No. 7, 2010, pp. 1574-1581. doi:10.1016/j.buildenv.2010.01.005

[3] Y. Bichiou and M. Krarti, "Optimization of Envelope and HVAC Systems Selection for Residential Buildings," Energy and Buildings, Vol. 43, No. 12, 2011, pp. 3373-3382. doi:10.1016/j.enbuild.2011.08.031

[4] K. F. Fong, V. I. Hanby and T. T. Chow, "HVAC System Optimization for Energy Management by Evolutionary Programming," Energy and Buildings, Vol. 38, No. 3, 2006, pp. 220-231. doi:10.1016/j.enbuild.2005.05.008

[5] H. Jedrzejuk and W. Marks, "Optimization of Shape and Functional Structure of Buildings as Well as Heat Source Utilisation Example," Building and Environment, Vol. 37, No. 12, 2002, pp. 1249-1253. doi:10.1016/S0360-1323(01)00100-7

[6] G. Rapone and O. Saro, "Optimisation of Curtain Wall Facades for Office Buildings by Means of PSO Algoritm," Energy and Buildings, Vol. 45, 2012, pp. 189-196. doi:10.1016/j.enbuild.2011.11.003

[7] N. Djuric, V. Novakovic, J. Holst and Z. Mitrovi, "Optimization of Energy Consumption in Buildings with Hydronic Heating Systems Considering Thermal Comfort by Use of Computer-Based Tools," Energy and Buildings, Vol. 39, No. 4, 2007, pp. 471-477. doi:10.1016/i.enbuild.2006.08.009

[8] V. Sambou, B. Lartigue, F. Monchoux and M. Adj, "Thermal Optimization of Multilayered Walls Using Genetic Algorithms," Energy and Buildings, Vol. 41, No. 10, 2009, pp. 1031-1036. doi:10.1016/j.enbuild.2009.05.007

[9] J. Ma, J. Qin, T. Salsbury and P. Xu, "Demand Reduction in Building Energy Systems Based on Economic Model Predictive Control," Chemical Engineering Science, Vol. 67, No. 1, 2012, pp. 92-100. doi:10.1016/j.ces.2011.07.052

[10] W. Wang, R. Zmeureanu and H. Rivard, “Applying MultiObjective Genetic Algorithmsin Green Building Design Optimization," Building and Environment, Vol. 40, No. 11, 2005, pp. 1512-1525. doi:10.1016/j.buildenv.2004.11.017

[11] M. Mossolly, K. Ghali and N. Ghaddar, "Optimal Control Strategy for a Multi-Zone Air Conditioning System Using a Genetic Algorithm," Energy, Vol. 34, No. 1, 2009, pp. 58-66. doi:10.1016/j.energy.2008.10.001

[12] L. Lu, W. Cai, L. Xie, S. Li and Y. C. Soh, "HVAC Sys- tem Optimization - In-Building Section," Energy and Buildings, Vol. 37, No. 1, 2005, pp. 11-22.

[13] L. Magnier and F. Haghighat, "Multiobjective Optimization of Building Design Using TRNSYS Simulations, Genetic Algorithm, and Artificial Neural Network," Building and Environment, Vol. 45, No. 3, 2010, pp. 739-746. doi:10.1016/j.buildenv.2009.08.016

[14] F. Engdahl and D. Johansson, "Optimal Supply Air Temperature with Respect to Energy Use in a Variable Air Volume System," Energy and Buildings, Vol. 36, No. 3, 2004, pp. 205-218. doi:10.1016/j.enbuild.2003.09.007

[15] E. Asadi, M. G. da Silva, C. H. Antunes and L. Dias, "Multi-Objective Optimization for Building Retrofit Strategies: A Model and an Application," Energy and Buildings, Vol. 44, 2012, pp. 81-87.

[16] G. Zemella, D. De March, M. Borrotti and I. Poli, "Optimised Design of Energy Efficient Building Facades via Evolutionary Neural Networks," Energy and Buildings, Vol. 43, No. 12, 2011, pp. 3297-3302. doi:10.1016/j.enbuild.2011.10.006

[17] V. Siddharth, P. V. Ramakrishna, T. Geetha and A. Sivasubramaniam, "Automatic Generation of Energy Conservation Measures in Buildings Using Genetic Algorithms," Energy and Buildings, Vol. 43, No. 10, 2011, pp. 2718-2726. doi:10.1016/i.enbuild.2011.06.028

[18] A. Saporito, A. R. Day, T. G. Karayiannis and F. Parand, "Multi-Parameter Building Thermal Analysis Using the Lattice Method for Global Optimisation," Energy and Buildings, Vol. 33, No. 3, 2001, pp. 267-274. doi:10.1016/S0378-7788(00)00091-8

[19] M. Hamdy, A. Hasan and K. Siren, "Impact of Adaptive Thermal Comfort Criteria on Building Energy Use and Cooling Equipment Size Using a Multi-Objective Optimization Scheme," Energy and Buildings, Vol. 43, No. 9, 2011, pp. 2055-2067. doi:10.1016/j.enbuild.2011.04.006

[20] M. Wetter, "BuildOpt-A New Building Energy Simulation Program That Is Built on Smooth Models," Building and Environment, Vol. 40, No. 8, 2005, pp. 1085-1092. doi:10.1016/j.buildenv.2004.10.003

[21] A. Hasan, M. Vuolle and K. Siren, "Minimisation of Life Cycle Cost of a Detached House Using Combined Simulation and Optimisation," Building and Environment, Vol. 43, No. 12, 2008, pp. 2022-2034. doi:10.1016/j.buildenv.2007.12.003

[22] H. Voll, T.-A. Kõiv, T. Tark and M. Sergejeva, "Cooling Demand in Commercial Buildings-The Influence of Daylight Window Design," WSEAS Transactions on Applied and Theoretical Mechanics, Vol. 5, No. 1, 2010, pp. 101111 .

[23] M. Wetter, "GenOpt(R) Generic Optimization Program, User Manual, Version 3.0.0," Lawrence Berkeley National Laboratory, Berkeley, 2009. doi:10.2172/962948

[24] T. Kalamees and J. Kurnitski, "Estonian Test Reference Year for Energy Calculations," Proceedings of the Estonian Academy of Science, Engineering, Vol. 12, No. 1, 2006, pp. 40-58.

[25] EN 15251:2007, "Indoor Environmental Input Parameters for Design and Assessment of Energy Performance of 
Buildings Addressing Indoor Air Quality, Thermal Environment, Lighting and Acoustics," 2007.

[26] Estonian Government Ordinance No. 258, "Minimum Requirements for Energy Performance of Buildings (20. 12.2007)," RT I 2007.

[27] J. Kurnitski, A. Saari, M. Vuolle, J. Niemelä and T.
Kalamees, "Cost Optimal and nZEB Energy Performance Levels for Buildings," Final Report, 2011.

[28] T. Rosencrantz, "Performance of Energy Efficient Windows and Solar Shading Devices, Evaluation through Measurements and Simulations," Lund University, Lund, 2005. 